\title{
Culture-Specific Characteristics of Alcohol Related Disorders and Culture- Sensitive Approach in Ethiopian Immigrants and Ethnic Arabic Groups in Israel
}

\author{
Paola Rosca1*, Danny Budowski² and Walid Haddad ${ }^{3}$ \\ ${ }^{1}$ Department for the Treatment of Substance Abuse, Mental Health Division, Ministry of Health, Israel, Hebrew University, Jerusalem, Israel \\ ${ }^{2}$ National Director of Ambulatory Services, Mental Health Division, Ministry of Health, Jerusalem, Israel \\ ${ }^{3}$ National Supervisor-Arab Sector, Israel Anti-drug Authority, Ministry of Public Security, Jerusalem Israel
}

\begin{abstract}
Israel, being a multi-cultural society, faces different unhealthy alcohol intake patterns among various ethnic groups, which in turn need to be addressed in a culture sensitive manner. This article focuses, as an example to the complexity of the issue, on two diverse ethnical groups- the new Jewish immigrants of Ethiopian origin and the Arab population in Israel.

The great heterogeneity within these two populations themselves is presented. The Arab speaking population is diverse- most of which are Muslims of different sects, including Bedouins, whose religion prohibits alcohol intake; Christians of different denominations, Druze, Samaritans and others. The Ethiopian "Beta Yisrael" (House of Israel) Jewish tribe, whose members have been immigrating to Israel since 1977, but what seemingly seems to be a homogeneous community, is in fact quite heterogenic culturally, when it comes to developing proper prevention and treatment programs. This heterogeneity finds its expression in varying alcohol intake patterns and epidemiology. Thus, cultural beliefs and behaviors relating to alcohol abuse and abstinence that are relevant to effective culture sensitive interventions are presented too.

But how can one plan effective preventive and treatment interventions to suit this heterogeneity? The Integrative Culture Sensitive Assessment and Treatment Model presented, delineates the major stages and the basic steps one must take to implement a culture sensitive preventive or treatment intervention, be it in an individual medical setting or a group or community based public health intervention. Finally, some insights as to culture sensitive interventions in treating alcohol related disorders are presented.
\end{abstract}

"Wine is not for kings... not for kings to drink, nor any strong drink for princes, lest they drink and forget what has been ordained and infringe on the rights of the poor. Give strong drink to the hapless and wine to the embittered. Let them drink and forget their poverty and put their troubles out of mind." (Proverbs 31, 4-7).

"Even if your illness [alcoholism] doesn't kill you, it'll still destroy your home." (Ethiopian proverb).

Keywords: Alcohol-related disorders; Addiction; Cultural sensitivity; Israel; Arabs; Ethiopian Jews; Cultural assessment

\section{Introduction}

Israel is a multi-cultural country; its population having grown nearly tenfold from 873,000 at the time of its establishment in 1948 to 8.3 million residents in 2015 . The major religious groups in Israel, characterized by different attitudes towards alcohol consumption, are Jews (accounting for about $75 \%$ of the population, including immigrants from former Soviet Union, Ethiopia and other countries), Muslim Arabs (constituting around 15\% of the population), Christian Arabs (6\%), a minority of Druze and others [1]. 27\% of the Jewish population is 1 st generation and another $33 \%$ are 2 nd generation in Israel due to massive "Aliya" ("progressing towards Jerusalem"- the immigration of Jews from the Diaspora to the land of Israel). Since the 1980s two large Jewish immigration waves arrived from Former Soviet Union and from Ethiopia. In 2014 more than 135,500 Jews of Ethiopian origin have been living in Israel and about two thirds of them were born in Ethiopia [2]. Alcohol related problems have increased in Israel during the last two decades especially among the youth, as a central leisure-time activity, thus becoming a major concern. Especially high rates of alcohol use have been reported among under-age Ethiopian pupils, even higher than among Russian origin ones [3]. Data on alcohol and drug use among immigrant youth in Israel show that first generation immigrants, born in their country of origin, showed higher alcohol consumption than Israeli youth but whilst second generation immigrant youth from FSU showed improved rates, Ethiopian secondgeneration youth showed increased misuse [4]. The Ethiopian group arouses major concern for alcohol use. This is true particularly for the Ethiopian youth which frequently engages in high-risk behaviors. When compared with a sample of boys from former Soviet Union and of Israeli origin, the Ethiopian youth reported higher rates of family unemployment, dependence from public welfare, violent behavior, last 30 day- consumption of beer and liquor and inferior school achievements, thus calling for specific ethno-cultural preventive and treatment interventions [5]. Due to the difficult acculturation process of these

*Corresponding author: Paola Rosca, Department for the Treatment of Substance Abuse, 39 Yirmiyahu St, Jerusalem, Israel; Tel: +972-506-242407; E-mail: paola.roska@MOH.health.gov.il

Received October 26, 2015; Accepted November 16, 2015; Published November 25, 2015

Citation: Rosca P, Budowski D, Haddad W (2015) Culture-Specific Characteristics of Alcohol Related Disorders and Culture-Sensitive Approach in Ethiopian Immigrants and Ethnic Arabic Groups in Israel. J Socialomics 4: 131. doi:10.4172/2167-0358.1000131

Copyright: ( 2015 Paola R, et al. This is an open-access article distributed under the terms of the Creative Commons Attribution License, which permits unrestricted use, distribution, and reproduction in any medium, provided the original author and source are credited. 
immigrants to Israel the lack of a "significant other", generally acting as a protective factor against high risk behaviors was typically observed. Among the Arabic cultural group in Israel a gradual expansion in the use of psychoactive substances, including alcohol, especially among adolescents, was also reported mainly due to its transformation since the 70 s from a traditional culture to a modern and secular one. The Arabic cultural group has special characteristics which differentiate it from the Jews, for example the fact that their religion prohibits alcoholic beverages while tobacco smoking is well-accepted and forms integral part of the social life. Moreover being alcohol prohibited by religion alcohol drinking is considered a social deviance, differently from the Jews, and as such it is considered a taboo and therefore alcohol is not consumed in public but in hidden places, such as orchards or olive trees fields, frequently together with drugs. Once the taboo border is trespassed the youth can easily access to drugs. Another possible reason for the increased use of alcohol and drugs among the Arabs is their lower socio-economic condition, compared to the Jews [6]. The increased alcohol and drug use among the Arabs compared to Jews, appears not only among the youth but also among adults, both men and women.

The former Soviet Union group differs from the two previous ones in that alcohol drinking was originally embedded in its culture and therefore its genetic and social characteristics are peculiar. Immigrants from Russia or former Soviet Union republics have very high levels of alcohol consumption and alcohol related problems [7] and constitutes a large, cohesive ethnic group, preserving many aspects of Soviet culture, attitudes and behaviors [8]. They immigrated from a society with high rate of alcohol consumption to Israel, which compared to Europe is still a low alcohol consumption society. Interestingly Russians who immigrated to Israel in the 80s seemed to adopt the low drinking patterns of native Israelis, whereas Russian immigrants in the 90s showed higher alcohol consumption than Israelis. This could be partly related to the fact that this wave of immigrants included people with partial non-Jewish ancestry, with less biological protection against alcoholism, secondary to alcohol de-hydrogenase genetic polymorphism [9]. Moreover many therapists in the field of addiction are from former Soviet Union countries and speak Russian so that referral and access to treatment of this group is much facilitated. Another important feature is the fact that Russian immigrants appear to show more permissive injunctive social drinking norms, indicating higher social acceptability of drinking [10]. Therefore in the present manuscript we decided to focus on the Ethiopian and the Arabic groups only, underlining their social and ethnic background, which have to be taken into account when programming culture-sensitive approaches to problem-alcohol drinking.

\section{Epidemiological Data}

Alcohol abuse in Israel, a country traditionally considered a "dry country" also due to the protective genetic low tolerance to ethanol, started to increase around the mid 90's after the huge immigration wave from Former Soviet Union Countries and continued to worsen up 2009 especially in the youth and young adults. HBSC survey data on Israel 11-15 years old showed that binge drinking sharply increased from $6.5 \%$ in 1994 to $20 \%$ in 2009 . In 2006 another preoccupying piece of data was published showing that 11 years old pupils reported drinking at least one alcoholic drink per week, a fact which ranked Israel as the second European Country after Ukraine [11]. As a consequence of this condition in 2010 Israel launched the National Alcohol Program in order to curb and reduce problem drinking and violence especially in the youth. This inter-Ministerial Program, coordinated by the IADA
(Israel Anti-Drug and Alcohol Authority) succeeded to bring about a reduction in the binge-drinking rates in the youth, which in 2011 dropped to $12.4 \%$ [4]. As the immigrants in Israel showed particularly high alcohol use several culturally sensitive programs were developed and tailored to suit the peculiar needs of Ethiopian, Russian and Arab sector populations and included preventive programs to improve public awareness of alcohol dangers both among adolescents, parents or significant adults.

\section{Alcohol, the Brain and Ethnicity}

Alcohol, whose intake is legal in Israel, is a depressant- that slows down the central nervous system and reduces vital functions, such as breathing, producing an initial sensation of calmness and lowering of inhibitions. The effects of alcohol differ from individual to individual, depending on how it is absorbed in the body, which differs according to: gender, age, body weight and mass, health condition, tolerance and speed of metabolism by various enzymes, e.g., alcohol dehydrogenase and CYTP450 2D6 [12,13]. Excessive drinking of alcohol causes physical, motor, cognitive and emotional damage. The biological basis for addiction is found in the mesolimbic centers of the brain (Ventral Tegmental Area, Nucleus Accumbens) and in the Orbito-frontal cortex though onset of addiction may occur only after years of excess drinking.

It was found that the ability of various ethnic groups and individuals to absorb and correctly metabolize alcohol is the outcome of the decades- old drinking habits of that group or individual, such that any group used to relatively little drinking of alcohol within a short period of time, that changes its consumption pattern to that of excessive or binge drinking, will likely find the high vulnerability of many of its members to serious damages due to alcohol [14].

\section{Alcohol and Ethiopian Immigrants}

In general, the rate of alcohol consumption in Ethiopia is considered to be low when compared to western countries and Israel [15] differing by regions and religions. The lowest prevalence is found in the dominantly Muslim rural areas and the highest is in urban areas, peaking in Addis Ababa. Approximately $40 \%$ of the adults and $31.6 \%$ of the adolescents reported drinking alcoholic beverages, $2.7 \%$ problematic drinking patterns, $1 \%$ alcoholism, mainly for males $[16,17]$.

Most alcoholic beverages consumed in rural areas are home-made beverages, some of which are homemade also in Israel [18].

Tella ${ }^{1}$, the most popular alcoholic beverage, has low alcohol content, ranging between 2\%-3.5\%. Other low-alcohol home-made drinks are also frequently consumed ${ }^{2}$ [19], as well as distilled beverages with higher alcohol concentration. ${ }^{3}[20]$.

Despite all the above descriptions, no studies have been conducted in Ethiopia as to consumption patterns of the Beta Yisrael. Several informants in Israel mentioned that there were some differences in

${ }^{1} T e l l a$ is an alcoholic, home-brewed beverage made of fermented cereal grains served at times in the evening with meals (as wine is served with a meal in France), or upon arrival of guests as a sign of respect.

${ }^{2}$ Korefe is a more concentrated version of tella, distilled through a cotton filter, which has $5 \%-6 \%$ alcohol. Another kind is called Kerari, known also as Asserwuham is a diluted and re-fermented tella, and contains much less alcohol and can be offered to children.

${ }^{3} T e j j$ is a honey wine with a higher concentration of alcohol $(6 \%-13 \%)$. This special drink is rare, expensive and only found in the homes of wealthy bee-keepers and served at special occasions and sipped in small quantities; Araki/Araqe or Katikala is a high alcohol concentration (22\%-28\%) home-made, distilled beverage, which when re-distilled, may reach alcohol levels of $45 \%-50 \%$ - then called Dagim Araki. 
alcohol consumption patterns in Ethiopia between the rural Jews and their Christian neighbors. The Jews seemingly produced less araki in their homes than their Christian neighbors and there were fewer cases of drunkenness and alcoholism, as it was also the case in the big cities.

On the other hand similar cultural behaviors to those of their Christian neighbors such as hospitality towards guests and celebrations, where offering of tella was an accepted practice, were observed; the Jews, being a minority group, had bigger influence of the extended family and leaders of the community on the individual, restraining excess alcohol drinking.

More than thirty years of ongoing immigration to Israel have created big differences between various groups of Ethiopian immigrants, depending on their areas of origin (Gondar, Tigray, Wolkait, Quara), their spoken languages (Amharic and Tigrinya), their different immigration routes and the duration of time till they arrived in Israel.

Former Ethiopians reached Israel via different paths that greatly influenced the degree of exposure to trauma, to different types of spirits and to unfamiliar drinking patterns.

Thus, for instance, those who immigrated in the period 1977-1989, mainly via Sudan, remained in transit camps under extremely harsh conditions, exposed to repeated traumas; many lost their lives en route and in the camps. Nonetheless, there was little exposure to alcohol. However, later immigrants ${ }^{4}$ who spent from several months up to 2 years in Addis Ababa awaiting their immigration had easy access to super-alcoholic drinks, with an increased risk of exposure. [21]

Immigration is a well-known significant stressor [22,23] and alcohol frequently serves as an escape mechanism for people in distress (see the introductory verses from Proverbs), or as a self-medication $[24,25]$ thus increasing the risk of abuse and dependence Table 1.

Partial data on those receiving Emergency Room (ER) treatment due to alcohol intoxication reveal that the rate of Ethiopian origin patients was two-fold the general population ( $3 \%$, as opposed to their being only $1.6 \%$ of the population), most of them (78\%) were young, aged 15-34. In one hospital they consisted of $10 \%$ of all those admitted, but the bias might be explained by the fact that the hospital was located near towns highly populated with Ethiopians [26].

\section{Cultural Aspects of Ethiopian Immigrants}

Some of the basic norms and expressions familiar to the Ethiopians despite their heterogeneity, and which might help in understanding their behavior, especially that of those living in segregation, will be presented. This knowledge might help during the intercultural contact with them, which is extremely significant for both the prevention and the treatment of the issues of harmful use of alcohol and drugs.

\section{The support systems}

The extended family (zemed) was the central support system for

\begin{tabular}{|l|c|c|c|c|}
\hline Adults & $\begin{array}{c}\text { Studying } \\
\text { youth }\end{array}$ & $\begin{array}{c}\text { Detached } \\
\text { youth }\end{array}$ & $\begin{array}{c}\text { Ethiopian } \\
\text { youth }\end{array}$ & Type of use \\
\hline $64.3 \%$ & $49.4 \%$ & $62.3 \%$ & $67.0 \%$ & $\begin{array}{c}\text { Use of alcohol during the past } \\
\text { year }\end{array}$ \\
\hline $25.0 \%$ & $30.0 \%$ & $49.0 \%$ & $43.0 \%$ & Drunkenness \\
\hline
\end{tabular}

Table 1: The use of alcohol in various populations in Israel.

${ }^{4}$ Immigrants from the "Solomon Operation", one of the most important and largest immigration wave from Ethiopia to Israel, which took place in 1991. the individual both at work as well as at social events, such as weddings, where alcohol was usually consumed together with others in a social manner, and not with the aim of getting drunk. It was unacceptable to drink alone. The conversations that accompanied drinking played an important role in the dissemination of information, catharsis and the release of daily stresses [27]. Unlike in Ethiopia, where celebrations were concentrated in certain seasons of the year, in Israel, they are spread out across the entire year and, due to their relative accessibility (a few hours ride, rather than days of weeks of walking), the rate of participation in these events is high, and alcohol is freely served and consumed. These disturbing phenomena prompted a public outcry warning by a number of religious leaders against the dangers of excessive drinking ${ }^{5}$ [27].

\section{The significance of the honor code and its expressions}

A clear-cut hierarchy existed in Ethiopia. At the top stood the religious leaders, followed by the regional elders and sages ${ }^{6}$; the women and the children were last. Representatives of the establishment were shown respect, though also suspected and feared, being figures of authority [28]. A central part of the honor code was the skill of selfcontrol, one expression of which was the ability to refuse a second drink. If someone drank until becoming drunk, that person would get a bad name and the social pressure on him to stop that behavior was enormous.

\section{Keeping secrets and emotions}

Due to their many suspicions regarding strangers, and especially representatives of the establishment, it was not considered proper to share secrets with them, nor emotions; such restraint is not characteristic of drunkards. The building of trust, which is a key process, essential for the treatment of risky situations, requires special consideration [29].

\section{Elongated narrative, metaphorical and indirect speech}

It is a highly-valued form of speech in Ethiopia. It emphasizes mastery of the secrets of the spoken language through the art of concealment and the granting of clues ${ }^{7}$ and may be highly frustrating for the non-Ethiopian caregiver [21].

Stomach aches-may frequently be used as idioms of distress, psychosomatic manifestations of mental suffering or depression ${ }^{8}$ [30]. The potential effects of traditional medical beliefs and treatments are crucial for planning adequate treatment strategies [31].

\section{Culture-sensitive translation and mediation, conversational complexity}

The use of metaphors is an additional cultural characteristic stressing the importance of the functions of culture-sensitive mediation and translation that are essential for treatment and prevention among Ethiopian immigrants who live in segregation. In such cases, cultural translation, including models of disease and illness [32], is indeed significant beyond mere literal translation in order to properly understand and relate to their idioms of distress [33].

${ }^{5}$ The Ethiopian community religious leaders are powerful and respected figures, called kessoch

${ }^{6}$ The sages are called smagleoch.

${ }^{7}$ This metaphorical and indirect way of speaking is known as semina work, i.e. wax and gold.

${ }^{8} \mathrm{~A}$ well-known Ethiopian saying that may illustrate this is: The stomach is wider than the entire world, for those who have patience, meaning that a patient can somatize and withhold troubles and suffering in the stomach, until it can contain no more and ' explodes '. 


\section{Socialization factors}

Quite a few of the significant socialization factors in Ethiopia lost most of their status and impact in Israel $[30,34,35]$ including their ability to influence the children to stop their risky behaviors. These and other changes also become significant stressors for both the adults and the children [36]. Moreover, in Israel, Ethiopian immigrants face new and significant changes in socialization factors, such as the loss of impact and degradation of family status perceived by men.

\section{Ethiopian Proverbs on Drunkenness}

Proverbs are very helpful in learning about a culture's attitude towards various phenomena, and in this case, its negative attitude towards drunkards [34,37] as is true of many other societies. The stigma towards alcoholics is cross-cultural, including Ethiopia, and places the responsibility for his/her deeds on the alcoholic, such that the social rejection of the alcoholic is even greater than that of the mentally ill [38].

"The drunk and the crazy person speak straight from the heart" In a culture that values self-control and keeping of secrets, a drunkard is compared to someone mentally ill who knows no boundaries, has no self-control or honor, and hurts people because he does not respect these values.

"The drunk and the crazy person are one and the same" As in the previous saying, here too a parallel is made with a crazy person, but there is also an additional, hidden message, that there is a subtle difference between them--that someone who is mentally ill is not in control of his actions due to insanity, while the drunkard cannot control his behavior due to the drinking, which is in his control and for which he is responsible.

"The drunkard tells the truth", but the truth he discloses is the unspoken one meant to be kept secret, especially in regard to family relations ${ }^{9}$.

\section{Alcohol Drinking in the Arab Population in Israel}

The use of alcohol among the Arab population in Israel has progressively increased during the last years, especially among the youth, although the consumption of alcoholic beverages is still less among Muslim Arabs, compared to Jews and Christian Arabs, due to religious prohibition and social discouragement of drinking, particularly among women, which are socially condemned if drinking. In the last years the consumption of alcoholic beverages has become frequent among Muslim adolescent boys and young men and it has become as a rite de passage from childhood to adulthood, as a measure of assertiveness, of independence and power. The drinking stage may be considered as a stage in life that a young Muslim is expected to grow out of, stopping drinking while becoming adult and more religious. In this sense drinking alcohol is perceived as a measure of religiosity [39]. This increase in alcohol consumption in the Muslim young males raises particular concern because while Jewish youth is exposed to messages encouraging responsible drinking and to preventive programs at school, no such educational lessons are imparted to the Muslim population, which constitutes the majority of the country`s Arab population, where alcohol is strictly banned, along with drugs. Moreover the majority of the Arab settlements, where most of the Muslim population lives lack the necessary financial resources to counteract this trend and to invest

${ }^{9} \mathrm{An}$ Ethiopian folktale about two drunken friends and their wives ends in the proverb mentioned at the articles beginning: "Even if your illness [alcoholism] doesn't kill you, it will still destroy your home." in prevention and social and cultural programs for youth. Few local shops or bars sell alcohol in Arab towns, so that they often leave their towns to purchase alcoholic drinks at gas stations, where they can buy more drinks at a lower price, thus increasing the risk of traffic accidents under the influence of alcohol. Due to the religious prohibition alcohol is consumed in secret, in cars, along the street-sides, or at weddings where it is drunk "under the table". Because of the difficulty to drink, whenever the occasion to drink appears, the Muslims tend to consume great quantities of alcoholic beverages and engage in binge-drinking. The cultural split between Jews and Arabs and the minority Arab`s population lack of respect for the State of Israel and its legal institutions further exacerbate the plights of alcoholics, who are insufficiently deterred by possible criminal records [8]. The Arab population is nowadays facing a struggle of identity and meaning in the country, a factor which increases distress and contributes to alcohol misuse. Another factor possibly influencing higher levels of alcohol consumption in the youth is the direct exposure to terrorism [40].

Islam is a religion of abstinence in contrast to the Judeo-Christian tradition that tolerates and even advocates moderate alcohol consumption at least for religious rituals [41]. The prohibition to drink alcohol repeatedly appears in the sacred Koran, for ex. Allah the prophet says:" Oh ye who believe! Wine and the game of chance and idols, and divining arrows are only an abomination of Shaytaan 's (Satan's) handiwork. So shun each of them that you may prosper [Al-Maaidah 5:90]. In moments of responsibility such as in prayer Muslims are warned not to use alcohol:" Oh ye who believe! Approach not prayers with a mind befogged by alcohol, until ye can understand all that ye say, nor in a state of ceremonial impurity. (4:43). In Sunan Abi Dawood (3189) it is written that:" Allah has cursed alcohol, the one who drinks it, the one who pours it, the one who sells it, the one who buys it, the one who squeezes it (the grapes), the one for whom it is squeezed, the one who carries it and the one to whom it is carried". There are many other reports which state that alcohol in strictly forbidden and is the mother of all evils, moreover whoever falls into this sin will be led to other evil actions. Hadith n.3392 (Sunan Ibn Majah, Book of Intoxicants, chapter 30) declares: "Anything that intoxicates in a large quantity is prohibited even in a small quantity". It has to be noted that although this strong religious prohibition against alcohol has not always been adhered to $[14,42]$, it poses a strong pressure among Muslims to conceal this behavior and its consequences. The association between alcohol drinking and socio-economic status is a complex one, with groups of higher socio-economic status exhibiting a higher prevalence of light to moderate drinking and groups of lower socio-economic status having elevated rates of problem drinking and alcohol dependence. Prevalence of binge-drinking in Israel is reported to be highest among Arab males (21.4\%), followed by Jewish males (15.2\%), Arab women (7.9\%), and Jewish women (4.0\%). A greater proportion of the Arab population is employed in manual labor or service industry, differently from the Jews and its socio-economic status is lower than the Jews. Rates of binge-drinking are higher among Jews of lower socio-economic status but the opposite is true for the Arabs, where higher binge drinking is associated with higher socio-economic class. For the Arab population higher education constitutes a protective factor against drinking [43].

The Arab population in Israel constitutes a culture in transformation [44] but it differentiates from other Middle East rural cultures, characterized by the educated youth leaving their villages in order to emigrate to foreign countries or to move to big towns in that the youth deliberately chooses to remain in their villages where they become powerful "agents of change" [45]. 


\section{Cultural Aspects among Muslim Arabs in Israel}

\section{Harmony with nature and the supernatural}

One of the dominant principles characterizing the Arabic culture in Israel is the importance of harmony and equilibrium between man, nature and the environment where he lives. The typical Arab strives to fulfill a spiritual life in complete harmony with nature and he believes in two different but parallel worlds: the world where he lives and the external world populated by "good " and "evil" spirits, influencing all human behaviors [46]. The good spirits will protect him only if he behaves and takes into consideration the others' needs. Moreover there exists a strong belief that Allah controls the destiny of every individual [47] and that prayer heals.

\section{The family and collectivism}

The Arabic culture has a strong collectivistic orientation both at the social and family level, while a more modern individualistic orientation is predominant in the Jewish culture [48]. The traditional Arabic culture makes use of extended familial networks to support crises, and it stresses the importance of the family needs and connections in comparison to friends or colleagues, which are second in importance. One of the most important kinship structures is the hamula, which includes a number of generations in a patri-lineal line having a common ancestor [49]. The hamula leader also serves as the spiritual and practical father of the whole group and he represents the group to the outside world guiding its actions. The elders are perceived as the source of wisdom and knowledge and are therefore strongly respected [50]. In case a member of the family becomes sick or has a health problem, the restoration of health is of concern to all family members.

\section{Gender roles}

The social structure is patriarchal and male dominant and women 's social status is contingent on being married and on motherhood and they are viewed as submissive, powerless and subservient [43]. Divorced women tend to be rejected by society and women who use alcohol are a minority and tend to hide their use not are condemned and rejected by society.

\section{Self-control and responsibility}

There exists a strong belief in the capacity to achieve self-control and self- discipline upon impulses and feelings and to take personal responsibility. The individuals are requested to show good temper, patience, avoid showing distress or despair even if the critical period lasts long and to courageously cope with painful moments in life [48].

\section{Somatization and use of metaphors and proverbs}

Arab patients' communication is impersonal and restrained and makes use of idioms of distress relying on a complex system of metaphors and proverbs. For an Arab client expressing his personal problems publicly or outside the family is seen as disloyal or as a sign of weakness. In considering the explanatory model of health and disease they tend to place particular emphasis on an external focus of control, including the intervention of the supernatural, through angels or jins or the participation of other people with the supernatural by means of evil eye or sorcery [51].

\section{The role of traditional healers}

Arab clients frequently refer to traditional healers to seek help and the integration between modern treatment systems and traditional healing systems is recommended in order to achieve greater success in treatment. These healers employ authoritarian methods, provide guidance, use a direct approach giving the patient the solution of his problems, they are active while the patient tends to be passive and the relationship between them and the patient in the healing process is similar to teacher and student [52]. These principles, including the importance of spirituality, have to be taken into account addressing problem drinking and planning successful treatment programs for this population as it has been shown that conventional rehabilitation programs for alcohol addiction, utilizing a western approach, show low success rates, around $3 \%$ only [53].

\section{The Integrative Culture Sensitive Assessment and Treatment Model}

There are several generalized culture sensitive models of treatment. Budowski and Ayecheh delineate in their Integrative Culture Sensitive Assessment and Treatment Model [54] the major stages and the basic steps one must take to implement a culture sensitive intervention, be it an individual medical intervention or a group or community -based public health one.

The major stages of the model are: Pre-intervention, e.g., defining the problem and the target population; Assessment of the actual need for Culture Sensitive intervention and spelling the needs out; Proper use of translation and cultural mediation services if needed; Mapping of the "Significant Others" and incorporating them in the intervention process; Eliciting groups' Explanatory Model (EM) of health and disease: (e.g., using Kleinman's model guiding questions) as part of intervention of a multi-professional staff [55]. Planning intervention accordingly; Mapping discrepancies between group's EM and those of the interveners; recruiting 'significant others' if needed and negotiating discrepancies between the EM's in a respectful manner clarifying mutually agreed upon parts of EM as well as those not agreed upon. Other factors that should be taken into account are cultural expectations on gender relations which could dictate the preferential use of same-gender therapists in order to increase cooperation and avoid confusion or sexual implications; Religious concepts and beliefs which may be successfully incorporated in the therapeutic process; The stigma connected with therapeutic settings, especially for women, who are frequently under-represented, which could be reduced integrating services into general medical clinics; Differences in temporal perceptions which can create frustrations and premature termination of treatment ; Cultural and political discriminations, causing increased stress and lack of trust [51].

As an outcome of all the above, a number of relevant culturesensitive principles are suggested:

\section{Principles stemming from the heterogeneity of the populations}

Berry's model of acculturation [56] comes in useful in making the initial diagnosis of target population or person's type of acculturation (Table 2).

Interventions involving those adults, who live in cultural segregation from the host country's culture, should be delivered in the mother

\begin{tabular}{|l|l|l|l|}
\hline \multicolumn{2}{|c|}{} & \multicolumn{2}{|l|}{ Positive relation to dominant society } \\
\cline { 3 - 4 } & yes & no \\
\hline $\begin{array}{l}\text { Retention of } \\
\text { cultural identity }\end{array}$ & yes & Integration & Segregation \\
\cline { 2 - 3 } & no & Assimilation & Marginalization \\
\hline
\end{tabular}


tongue (Amharic, Tigrigna, Arabic) and based on home culture.

Interventions with marginalized young people should be streetbased and adapted to detached youth culture, with an understanding of the cultural roots on which they were raised at home.

\section{Principles stemming from the question: Is drinking alcohol a disease or a cure?}

For those whom drinking is a form of self-medication for coping with (or escaping from) distress, excessive use of alcohol is an outcome, meaning that the main thrust of any prevention program must be to handle the basic causes of that distress (the lack of decent housing, employment or education; family disintegration; the loss of parental authority, alienation, culture shock, political discriminations etc.). Such a program should include the promotion of a healthy lifestyle, especially in regard to the use of alcohol (supervised drinking) and ensure psycho-social and economic stability.

The segregated alcoholics ('the drunks') require out-reach programs conducted by experienced adult counselors, who speak the language and know the culture, and can work with the natural peer groups of the heavy drinkers at the place where they gather. These counselors can organize natural groups of heavy drinkers and create suitable therapeutic surroundings with the assistance of their families and significant others throughout their rehabilitation periods. The suggested approach is a combination of outreach, followed by a short intensive detoxification (detox) program, culturally adapted to the population under treatment, followed in turn by long term rehabilitation programs. These programs should also include spiritual counseling for the believers in order to alleviate hopeless-ness.

The marginalized alcoholics require a combination of outreach and existing programs, run by a care-giving team expert in the cultural background of these people. Due to their suspicious natures and lack of trust in the establishment, it is necessary to do much informal outreach work.

\section{Discussion}

Israel, being a country of immigration of Jews from all over the world such as from Former Soviet Union Countries or Ethiopia, living together with native Jews and ethnic Arab populations of different religious creed faces great challenges in planning adequate treatment services for alcohol problems adapted to the different cultural groups. This issue requires the formation and education of multi-disciplinary staff in the field of culture sensitivity and ethno-psychiatry. In 2011 the understanding of the importance of relating to the ethnic background of patients prompted the Ministry of Health to issue a regulation for culture-sensitive improved accessibility to health services, in an effort to reduce inequality gaps. The regulation requires lingual and cultural mapping of the potential clients' translation of all relevant medical information, including patients' bill of rights and websites into different languages, including Arabic and Amharic, prompting the use of cultural mediators or translators when needed, planning culturesensitive programs, and adapting the medical interventions to the ethnic background of patients in order to improve equality in health [57]. The increase in the use of alcoholic beverages in Israel during the last decade especially among young people, with a particular stress on immigrant, detached or minority youth, inspired new policy and strategy directions aimed at providing population and culture specific resources to help reduce the rates of use [58]. Moreover the effort of IADA (Israel Anti-Drug and Alcohol Authority) in conducting projects-evaluation research showed that alcohol rehabilitation and detoxification programs based on western principles were unsuccessful for most Ethiopian immigrants and for the Arab population. This triggered the planning of tailor-made culture-sensitive programs both for adults and young people, bringing about better adherence to the programs, cooperation and timely termination. In a period of globalization and multi ethnicity the development of such programs in the field of alcohol addiction is recommended. While there do exist clear differences among the various ethnic backgrounds, requiring specific adaptations, the knowledge of basic and general principles guiding to the planning of adequate culture-sensitive programs is of outmost importance. Lately the Ministry of Health together with Tel Aviv Sackler Medical School organized a practical course on culturesensitive principles for mental health professionals aiming to improve awareness of this important dimension among the therapists. We believe that the implementation of these programs on a large scale all over the country will bring about more successful rehabilitation rates in alcoholic patients.

\section{Conclusions}

Recently the need to adapt treatment services for addiction to different ethnic population has emerged all over the world. In our article we illustrated some specific cultural aspects of two different populations in Israel: Ethiopian immigrants and second generation subjects and ethnic Muslim Arabs, crucial for the planning of culturalsensitive programs for harmful drinking and alcoholism. More program-evaluation research is needed to assess the efficacy of these programs as well as formation courses for the therapists in order to achieve optimal results. We wish to conclude with the citation of an Ethiopian proverb, stressing the importance of treating patients with their own cultural principles: "The weed of the land should be plowed by an ox from the same land."

\section{References}

1. Neumark YD (2007) Alcohol Drinking Patterns and Prevalence of Alcoho Abuse and Dependence in the Israel National Health Survey. Isr J Psychiatry Relat Sci 44: 126-135.

2. http://www.cbs.gov.il/reader/newhodaot/hodaa_template $\mathrm{html}$ ?hodaa $=201411314$

3. Edelstein A, Bar-Hamburger R (2007) Patterns of drugs and alcohol abuse among youth from FSU and the connection to delinquency, to violence and to identity, National Anti-Drug and Alcohol Authority (IADA), Jerusalem, Israel.

4. Harel-Fisch $Y$ (2013) Trend of substance use among Israel youth: Findings from the Israel HBSC survey 1994-2011, National Anti-Drug and Alcohol Authority (IADA), Jerusalem, Israel.

5. Isralowitz R, Reznik A (2014) Ethiopian origin high-risk youth: A cross-cultura examination of alcohol use, binge drinking, and problem behavior. J Ethn Subst Abuse 13: 179-184.

6. Tal-Sapiro U (2014) Drug use among the Arab sector, Center for Research and Information, Knesset, Israel.

7. Harel-Fisch Y, Aziza F, Shaham M, Abu-Saaba H (2010) The Use of Psychoactive substances among Arab youth in Arab cities and in mixed cities in Israel, National Anti-Drug and Alcohol Authority(IADA), Jerusalem, Hebrew, Israel.

8. Winer S (2014) Concerns raised over Arab youth`s drug, alcohol abuse.

9. Kaptsan A, Telias D, Bersudsky Y, Belmaker H (2006) Ethnic origin of alcoholics admitted to an Israeli Treatment Centre. Amer J Drug \& Alcohol Abuse 32: 549553.

10. Shmulewitz D, Wall MM, Keyes KM, Aharonovich E, Alvadan C, et al. (2012) Alcohol use disorders and perceived drinking norms: Ethnic differences in Israeli adults. J Stud Alcohol Drugs 73: 981-990.

11. Harel- Fisch $Y$ (2013) The changing patterns of drug and alcohol use among Israeli youth: Innovative national and community -based intervention strategies. 
Citation: Rosca P, Budowski D, Haddad W (2015) Culture-Specific Characteristics of Alcohol Related Disorders and Culture-Sensitive Approach in Ethiopian Immigrants and Ethnic Arabic Groups in Israel. J Socialomics 4: 131. doi:10.4172/2167-0358.1000131

Presentation, National Anti-Drug and Alcohol Authority (IADA), Jerusalem, Hebrew, Israel.

12. Rosca P (2008) The Pharmaceutical Treatment of Alcoholism (1stedn), Addictions, Violence and Sex Offenses: Treatment in Light of the Law: Carme Pub. House, Jerusalem Israel 57-67

13. Zhou SF (2009) Polymorphism of Human Cytochrome P450 2D6 and Its Clinical Significance: Parts I+II, Clinical Pharmacokinetics 48: 689-723.

14. Neumark Y, Schwartz HS (2009) The epidemiology of alcohol use and dependence in Israel. Psychiatric and Behavioral disorders in Israel, Gefen Publishing House, Jerusalem, Israel 131-148.

15. World Health Organization (2013) World Health Statistics. Geneva: WHO. 111

16. Alem (1997) Mental Health in Rural Ethiopia: Studies on Mental Distress, Suicidal Behavior and the Use of Khat and Alcohol, Umea University Medical Dissertation: New Series 532

17. Zein ZAJ (1988) Poly-drug abuse among Ethiopian University students with particular reference to Khat. J. Trop Med \& Hygiene 91: 71-75.

18. Weiss S (2008) Alcohol Use and Abuse among Ethiopian Immigrants in Israel: A Review, African Journal of Drug and Alcohol Studies 7: 27-41.

19. Selinus R (1971) The traditional foods of the central Ethiopian Highlands, Uppsala, Scandinavian Institute of African Studies.

20. Desta B (1977) A Survey of the Alcohol Content of Traditional Beverages. Ethiop Med J 15: 65-68.

21. Budowski B, Rosca P, Witztum E (2014) Alcohol and drugs among Ethiopian Immigrants: culture sensitive aspects. Social, Cultural and Clinical Aspects of Ethiopian Immigrants in Israel, Ben Gurion University Press, Beer- Sheba 185210.

22. Mirsky J (2009) Mental Health Implication of Migration: A Review of Mental Health Community Studies on Russian-Speaking Immigrants in Israel. Soc Psych \& Psych Epidemiol 4: 179-187.

23. Ponizovsky AM, Radomislensky I, Grinshpoon A (2009) Psychological Distress and Its Demographic Associations in an Immigrant Population: Findings from the Israeli National Health Survey, Australia \& New Zeal J of Psych 43: 68-75.

24. Khantzian EJ (1997) The Self-Medication Hypothesis of Drug Use Disorders: Reconsideration and Recent Applications. Harv Rev of Psych 4: 231-244.

25. Budowski D (2008) Culturally-Sensitive Aspects in Risky Situations among Immigrants, More Control, Less Restraint: Prevention and Coping with Violence. Jerusalem: Israel Ministry of Health, Jerusalem, Israel. 5 7-59

26. Beer M, Reiss A, Berkowitz M (2003) Clinical characterization of children and adolescents admitted to the emergency room at Assaf Ha Rofeh following drug or alcohol use, National Anti-Drug and Alcohol Authority (IADA), Jerusalem, Israel.

27. Rosen C, Shmuel N (2007) From 'Tella' to 'Goldstar': the dangers of alcoholism among Ethiopian immigrants: A serious warning, Ministry of Absorption, Jerusalem, Israel.

28. Benezer G (1985) The Code of Honor: Psycho-Cultural Characteristics of Immigrants from Ethiopia: Misunderstandings during Contact with Israel, Leaves.

29. Budowski D, David J, Rosen H (1989) Customs and culture: Implications for the development of a professional connection, Betachin, Jerusalem, Israel.

30. Budowski D, David J, Eran Y (1994) The Family and Life Cycles of Ethiopian Jews during Intercultural Transition, Betachin, Jerusalem, Israel.

31. Danino D, Zohar A (2008) Ethiopia in Israel: An Ethno-pharmacological Study of the Ethiopian Immigrant Community, Medicine, Hebrew 7: 147-150.

32. Kleinman A (1978) Concepts and a model for the comparison of medical systems as cultural systems, In: Social Science \& Medicine- Part B, Medical Anthropology. Nord Pub, Hebrew 12: 85-93.

33. Budowski D, David J, Eran Y (1990) Issues in the Treatment of Families from Different Cultures: The Example of Ethiopian Jewry. Jerusalem, Betachin, Hebrew.

34. Rosen C (1986) Language and Food as Communication Mediators, Ministry of Absorption, Jerusalem, Israel.

35. Roer D, Strier R, Strier (2006) Immigrants in Israel: From the Deficit Theory to the Theory of the Founding Fathers, Ministry of Welfare, Jerusalem, Israel.

36. Budowski D, Kessel D, Avrahamoff (1987) How the social system manages the crisis situations of Ethiopian immigrants in the Absorption system. Treating problems of immigrants from Ethiopia. Youth Alyah, Jerusalem, Israel, Hebrew $21-41$

37. Budowski D, David J (1995) Alcohol:Dilemmas in Health Promotion with Ethiopian Immigrants (1stedn), Alcohol and Media Campaigns, EFSHAR Association, Jerusalem, Israel 66-78.

38. Schomerus G (2010) The Stigma of Alcohol Dependence Compared with Othe Mental Disorders: A Review of Population Studies, Alcohol \& Alcoholism 46: 105-112.

39. Baron-Epel O (2014) Alcohol Consumption among Arabs in Israel: A qualitative Study, Subst Use and Misuse 1-6.

40. Schiff M, Rahav G, Teichman M (2005) Israel 2000: immigration and gender differences in alcohol consumption. Am J of Addict? 14: 234-247.

41. Kotek SS (1989) Do not drink wine or strong drink: Alcohol and responsibility in ancient Jewish sources, Med \& Law. Hebrew 8: 255-259

42. Weiss S (2000) Trends of alcohol consumption in Israel-1990-1998. Alcologia 12: $27-30$.

43. Neumark YD, Rahav G, Jaffe DH (2003) Socio-economic status and binge drinking in Israel, Drug and Alcohol Depend 69: 15-21.

44. Al-Haj M (1987) Social change and family processes. Westview, London UK.

45. Aziza F, Brodesky G (1995) Changes in the Arabic family and development of services for the Arab elderly in Israel during the last decade, Gerontology, Hebrew.70: 69-80.

46. Haj M, Echee (1985) Traditionalism and modernism in the Arabic cultureorientation concerning the mentally ill, Trends to employ mentally ill patients, M.A Thesis, Faculty of Social Work, Hebrew University, Jerusalem, Israel, Hebrew.

47. Knaana S (1982) Change and Continuation, The Association for Arab Research, Jerusalem, Israel.

48. Barakat $H$ (1985) The Arab family and challenge of social transformation, (1stedn), Women and the family in the Middle East: New voice of change Austin, University of Texas Press.

49. Al-Krenawi A (1998) Family therapy with a multiparental/ multispousal family. Fam. Process 37: 65-82.

50. El-Islam MF (1989) Collaborations with families for rehabilitation of schizophrenic patients and the concept of expressed emotion. Acta Psychiatr Scand 79: 303-307.

51. Al-Krenawi A, Graham JR (2000) Culturally sensitive social work practice with Arab clients in Mental Health settings, NASW.

52. Al-Krenawi A, Graham JR (1996) Social work practice and traditional healing rituals among the Bedouin of the Negev. Internat Soc Work 39: 177-188.

53. Haddad W (2004) Use of alcohol and drugs among the youth In Israel and in the Arab Sector. Personal Communication, National Anti-Drug and Alcohol Authority (IADA) Jerusalem, Israel.

54. Budowski D, Ayecheh S (2013) Issues in cultural competence in Health Services: The example of Ethiopian immigrants to Israel. $3^{\text {rd }}$ European Transcultural Nursing Association (ETNA), International Conference, Israel, $\mathrm{Ha}$ Goshrim, Proceedings 1-30.

55. Kleinman A (1978) Concepts and a model for the comparison of medica systems as cultural systems, Social Science and Medicine, Part B: Medical Anthropology 12: 85-93.

56. Berry JW (1997) Immigration, acculturation and adaptation, Applied Psychology: An international Review 46: 5-68.

57. Ministry of Health, Director General Regulation (2011), Jerusalem, Israel, Hebrew.

58. Walsh S, Harel- Fisch Y, Fogel- Grinwald H (2010) Parents, teachers and pee relations as predictors of risk behaviors and mental well-being among immigrant and Israeli born adolescents, Social Science \& Medicine 70: 976-984 